Check for updates

Cite this: RSC Adv., 2017, 7, 42036

Received 27th June 2017

Accepted 23rd August 2017

DOI: $10.1039 / \mathrm{c} 7 \mathrm{ra0} 07104 \mathrm{c}$

rsc.li/rsc-advances

\title{
Advances in chitosan-based superabsorbent hydrogels
}

\begin{abstract}
Baoxiao Cheng, Boying Pei, Zhengke Wang ${ }^{D}$ * and Qiaoling Hu
Superabsorbent hydrogels (SHs) have been used in many fields in recent years. Also chitosan-based superabsorbent hydrogels have attracted great attention because of the excellent properties of chitosan such as biocompatibility, biodegradability and antibacterial properties. This review focuses on the recent progress in chitosan-based superabsorbent hydrogels, providing a brief overview of the preparation approaches, the effects of preparation conditions on the structures and water absorbency performance, chitosan-based composite hydrogels comprised of inorganic fillers, other natural polymers as well as their derivatives, and promising applications for biomedical and personal hygiene, agriculture and water treatment.
\end{abstract}

\section{Introduction}

Superabsorbent hydrogels (SHs) are three-dimensional (3D) and highly hydrophilic networks of polymer chains which imbibe more than 100 times their dry weight of water. ${ }^{1}$ The excellent water absorbency of these materials results from the presence of a great number of hydrophilic groups on the polymer chains such as carboxyl, amino, amide, hydroxyl and sulfonic. ${ }^{2}$ Due to these functional groups, the water absorbency behaviour of SHs is often sensitive to the $\mathrm{pH}$ and ionic strength of the swelling solution. Thus, they can respond to the stimuli of the surrounding environment. Therefore, these good properties have drawn significant attention for applications in personal hygiene, ${ }^{3}$ agriculture, ${ }^{4,5}$ construction and building, ${ }^{6,7}$ water

MOE Key Laboratory of Macromolecular Synthesis and Functionalization, Department of Polymer Science and Engineering, Zhejiang University, Hangzhou 310027, China. E-mail:wangzk@zju.edu.cn purification, ${ }^{8}$ drug delivery and controlled release, ${ }^{9-11}$ and biomedical applications. ${ }^{12}$

Currently, most of the commercially available and disposable superabsorbent products such as baby diapers are made from petroleum-based vinyl monomers, and thus they are poor in degradability and environmental friendliness. With the concept of environmental protection and the rising of green chemistry, materials' biodegradability has been widely focused on. ${ }^{13}$ Therefore, utilization of biodegradable and renewable polymers has drawn much attention owing to their abundant resources, low production cost and biodegradability. Recently various natural polymers are used to develop eco-friendly superabsorbent hydrogels, such as starch, ${ }^{14}$ cellulose ${ }^{15}$ chitosan, ${ }^{16}$ cashew gum, ${ }^{17}$ konjac glucomannan, ${ }^{18}$ rice husk, ${ }^{19}$ raw bran, ${ }^{20,21}$ xyloglucan, ${ }^{22}$ tulips, ${ }^{23}$ and even yeast. $^{2}$

Chitosan (CS), a derivative obtained by the partial deacetylation of the $N$-acetyl group from chitin which is the second

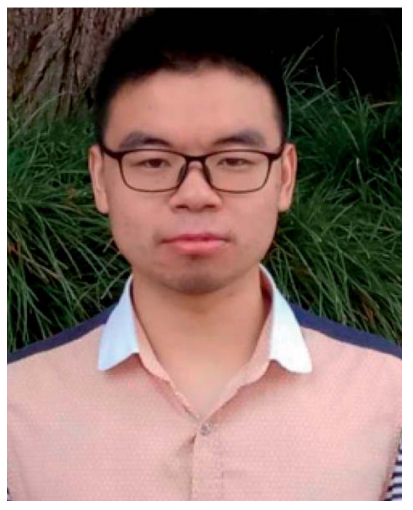

Baoxiao Cheng is a graduate student under the supervision of Professor Zhengke Wang in the Department of Polymer Science and Engineering of Zhejiang University. His research interest focuses on the high strength and self-healing hydrogels.

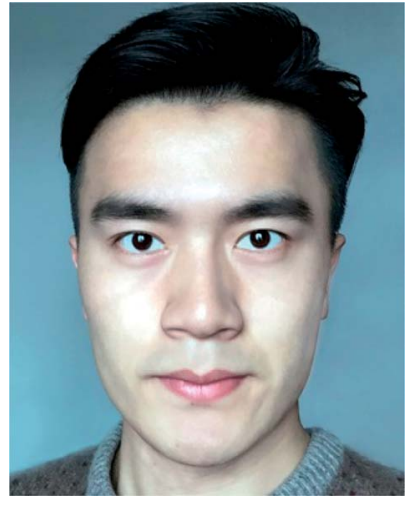

Boying Pei received his B.E. at Sichuan University in 2016. Currently, he is pursuing his Master degree in the Department of Polymer Science and Engineering of Zhejiang University. His research focuses on chitosan-based biomaterials and biomineralization. 
most abundant natural polysaccharide. It is a linear copolymer composed of $\beta_{1-4}$ linked $N$-acetylglucosamine (GLcAc) units and glucosamine $(\mathrm{GLCN})$ units, with the similar molecular structure as cellulose and chitin..$^{\mathbf{2 4 , 2 5}} \mathrm{CS}$ can differ in degree of deacetylation (DD) and molecular weight. The DD of CS is determined by two-abrupt-change potentiometric titration method and calculated using the eqn $(1)^{25}$

$$
\mathrm{DD}=\frac{\Delta \nu \times C_{\mathrm{NaOH}} \times 10^{-3} \times 16}{m \times 0.0994} \times 100 \%
$$

where $C_{\mathrm{NaOH}}$ and $\Delta \nu$ stand for the concentration and volume of $\mathrm{NaOH}$ consumption between the two abrupt changes of $\mathrm{pH}$, respectively, $m$ is the dry weight of a CS sample. Since the multiple hydrogen-bonds between macromolecular chains, CS cannot be directly dissolved in water or organic solvent. But it is soluble in dilute acetic acid aqueous solution as used mainly solvent for CS due to the protonation of the amino groups at low $\mathrm{pH}$. It is important to note that CS can also be dissolved in LiOH/urea aqueous solution via the freezing-thawing process. $^{26}$

CS has good antibacterial property, biocompatibility and biodegradability. ${ }^{27}$ It has reactive amino $\left(-\mathrm{NH}_{2}\right)$ and hydroxyl $(-\mathrm{OH})$ groups that are convenient for graft polymerization of hydrophilic vinyl monomers under mild reaction conditions. ${ }^{28}$ Due to the existence of amino groups, chitosan-based SHs not only possess a good water absorbent, but also has antibacterial activities. ${ }^{29}$ With these outstanding features, chitosan-based SHs may have more potential applications in the future.

\section{Preparation methods}

The networks of superabsorbent hydrogels can be achieved by covalent bonds, ionic or strong physical interactions. ${ }^{30} \mathrm{We}$ classify these cross-links into two types: chemical cross-linking methods and physical cross-linking methods.

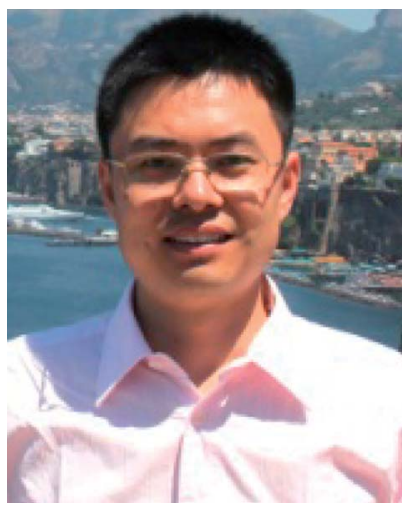

Zhengke Wang received his Ph.D degree at Zhejiang University in 2009. In 2009-2012, he carried out his postdoctoral work at Zhejiang University and Hongkong University of Science and Technology. He is currently associate professor in the Department of Polymer Science and Engineering at Zhejiang University. He has been published more than 40 peer reviewed articles in Nature Communications, Journal of the American Chemical Society, etc., and granted 24 China and US patents. And he is the reviewer for Advanced Functional Materials, Materials Horizons, ACS Biomaterials Science \& Engineering, etc. His research interests are focused on Natural Materials and Biomaterials.

\subsection{Chemical cross-linking methods}

Chemical techniques, such as aqueous solution polymerization, suspension polymerization, are commonly used for the preparation of chitosan-based superabsorbent hydrogels. According to the reaction mechanism, this review classifies the chemical methods into the following two types: free radical inducing polymerization and non free radical polymerization.

2.1.1 Free radical inducing polymerization. Free radical inducing polymerization is a typical and extensively used approach for the preparation of SHs. The majority of the recently studied chitosan-based superabsorbent hydrogels are based on cross-linked poly(acrylic acid), poly(acrylamide) or other hydrophilic vinyl monomers via this method because it is convenient, highly efficient and easily polymerized to form a higher molecular weight polymer. ${ }^{31}$ The prominent induction method is chemical induction, such as thermal initiators (e.g. ammonium persulfate), ${ }^{16,32-34}$ redox induced systems, ${ }^{35-37} \mathrm{Ce}(\mathrm{Iv})$ induction $^{25,38}$ and photoinitiator. ${ }^{28}$ In addition, physical induction methods like Co-60 $\gamma$ radiation, ${ }^{39-42}$ electron beam irradiation $^{43}$ and photo-induction with UV light ${ }^{44,45}$ are also employed.

A large number of researches have elaborated the process of free radical induced polymerization of chitosan-based grafting polymers as the following: the chitosan backbone produces chitosan-substrate free radicals by initiators, and then the macro-radicals initiate the vinyl monomers to copolymerize to form the grafting copolymers, and 3D network structure is formed in the presence of cross-linkers. The self-polymerization of monomers and cross-linking reactions between monomers and cross-linkers can take place at the same time. Therefore, the grafting product is a mixture including chitosan- $g$-PAA, PAA and cross-linked PAA. Although most of these reported articles proposed the similar process, they failed to further demonstrate the grafting mechanism by any convincing experiment or characterization. For example, G. R. et al. ${ }^{16}$ proposed the reaction process of chitosan- $g$-poly(acrylic acid-co-acrylamide)

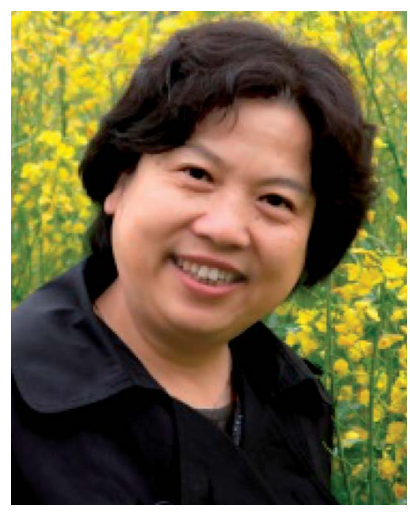

Qiaoling Hu received her master degree at Chemistry Department of Hangzhou University in 1996. She got her Ph.D. degree on material science at Zhejiang University and became a professor in the Department of Polymer Science and Engineering at Zhejiang University in 2004. She was a senior visiting scientist of Harvard-MIT Division of Health Sciences and Technology in 2009. She has been published more than 70 peer reviewed articles in Nature Communications, Biomaterials, etc., and granted 26 China patents. Her research interests are focused on natural polymer for biomedical applications, and more than 10 research findings have been applied in clinic. 
superabsorbent hydrogels by free radical polymerization in Fig. 1. First of all, potassium persulfate, as an initiator, produced the initial free radicals under heating, and then these radicals extracted hydrogen from the hydrogen groups of the chitosan backbone to form alkoxy radicals on the substrate. So, this persulfate-saccharide redox system results in active centers on the substrate to radically initiate polymerization of acrylic acid (AA) and acrylamide (AAm) led to a graft copolymer. Since the presence of $N, N$-methylenebisacrylamide (MBA) as crosslinker, the grafting copolymer forms a cross-linked structure. The preparation process mainly proceeds in acetic acid aqueous solution to dissolve chitosan. Also, CS can be dissolved in $\mathrm{LiOH} /$ urea aqueous solution and the inducing process is similar to the acid solvent system. ${ }^{46}$

Preparation conditions during free radical polymerization significantly affect the structure of the superabsorbent hydrogels and their water absorption properties..$^{35,47,48}$ For instance, the effects of conditions are mostly investigated such as reaction temperature, reaction time, neutralization degree of $\mathrm{AA}$, the amount ratio of AA to chitosan, the $\mathrm{pH}$ of external solution, and the amount of initiators, cross-linkers and monomers. ${ }^{12,16,46,49-55}$ And a $2^{4-1}$ fractional factorial design is used to evaluate the effects of these parameters. ${ }^{56,57}$ As the amount of initiators increases, the macro radicals increases, and thus more acrylic acid are grafted onto the chitosan, which means that the average kinetic chain length of PAA becomes shorter, and this improves the water absorbency. However, if the amount of initiators increases further, more radicals will accelerate the terminating step via bimolecular collision, and

\section{(1) Initiators produce free radicals}

$$
\mathrm{I} \longrightarrow \mathrm{I}
$$

(2) Chitosan produces macro free radicals by initiators

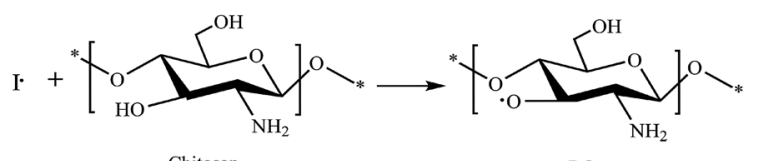

Chitosan

RO $\cdot$

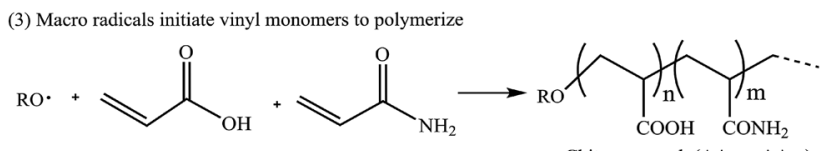

AA AAm Chitosan-g-poly(AA-co-AAm)

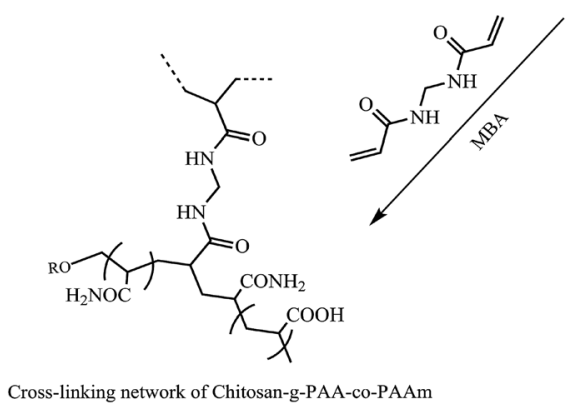

Fig. 1 General mechanism for radical graft polymerization of acrylamide and acrylic acid onto chitosan in the presence of MBA as cross-linker. Reproduced from ref. 16. Copyright (2004), with permission from Elsevier. the molecular weight of the branch chain will decrease. As a result, the water absorbency of the product decreases. ${ }^{58}$ It is worth noting that the persulfate initiators can not only initiate the grafting copolymerization, but also give rise to degradation of chitosan backbone greatly in a very short time when KPS is added to the chitosan solution at $70{ }^{\circ} \mathrm{C}$, which has been demonstrated by Hsu et al. ${ }^{59}$ It is considered that the anionic free radicals, ${ }^{-} \mathrm{SO}_{4}{ }^{-}$attack at the $\mathrm{C}-4$ or $\mathrm{C}-1$ atoms of the backbone rings, then cause breakage of the adjacent $\mathrm{C}-\mathrm{O}-\mathrm{C}$ glycosidic bonds in the main chain and creates free radicals at the chain ends which can polymerize with other monomers to form a block copolymer shown in Fig. 2. To solve this problem, superabsorbent hydrogels of chitosan- $g$-polyacrylamide can be prepared via UV irradiation or microwave irradiation in the absence of any initiator. For example, a hydrogel is obtained by UV irradiation without photoinitiator, and owing to the absence of any initiator, this hydrogel is completely transparent and free from any impurities. ${ }^{45}$ And without any free radical initiators, a more efficient grafting in the synthesis of chitosan-graftpoly(acrylonitrile) under microwave irradiation is observed compared with conventional grafting copolymerization using redox initiator. A possible and reasonable grafting mechanism under microwaves in the absence of initiators was proposed in Fig. $3 .^{60}$

In addition to the initiator, cross-linkers play the major role in the formation of hydrogels and their performance such as

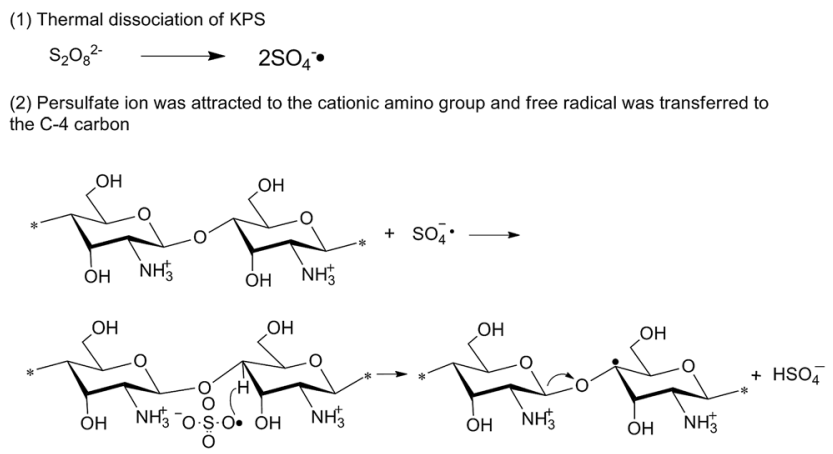

(3) Chain scission at the C-O-C bond

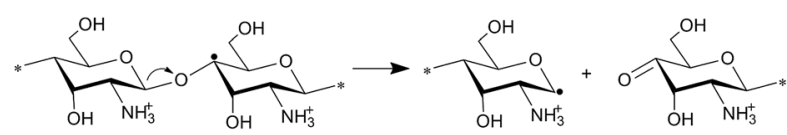

(4) Inhibition of free radical by degraded chitosan chain with carbonyl group at the end

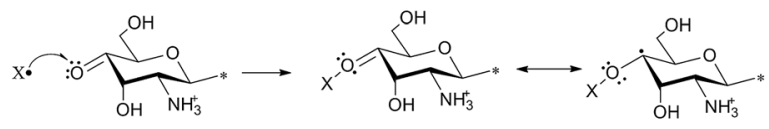

(5) Deactivation of persulfate ions

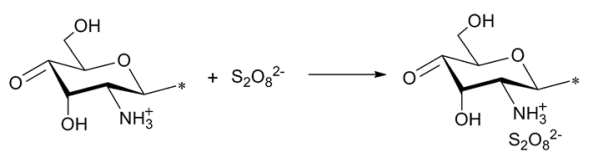

Fig. 2 The proposed mechanism for the degradation of chitosan by KPS free radical. Reproduced from ref. 59. Copyright (2006), with permission from Elsevier. 
Grafted at $\mathrm{O}+\mathrm{H}$ groups of chitosan

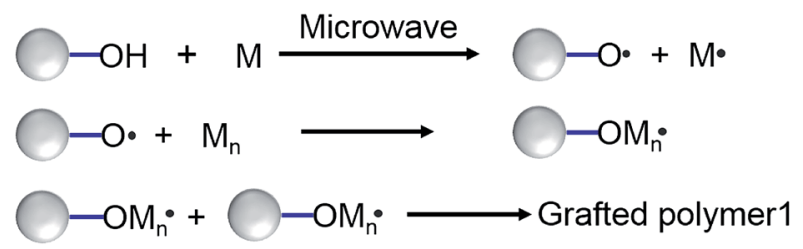

Grafted at $\mathrm{NH}_{2}$ groups of chitosan

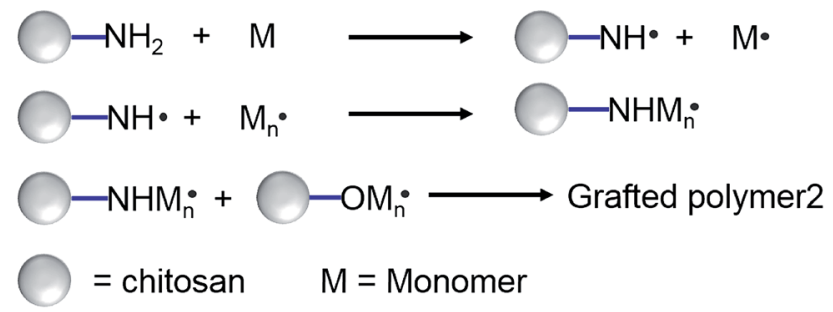

Fig. 3 Grafting mechanism of chitosan under microwave irradiation. Reproduced from ref. 60. Copyright (2004), with permission from Wiley-VCH.

water absorbency and mechanical strength. The weak mechanical properties of chemical cross-linked hydrogels are due to the inhomogeneous network structure generated during the polymerization, which are demonstrated by spatially nonuniform cross-linking densities and randomly distributed chain lengths between the cross-links. ${ }^{1,61,62}$ The cross-linking of SHs is mostly achieved by multifunctional vinyl monomers such as MBA. Their reactivity ratio affects the amount of soluble polymer and the uniformity of network formed during the polymerization..$^{63,64}$ If the reactivity of the cross-linker is lower than the monomers, a uniform network can be formed. Otherwise, a heterogeneous network and more soluble polymer are obtained. It is due to the cross-linker with higher reactivity is more likely to be incorporated in the network in the early period of polymerization and consumes rapidly resulting in high crosslinking densities, and then less is left which will be incorporated in the network in the late polymerization. Therefore, the late formed hydrogel has low crosslinking densities meanwhile many soluble polymer are not connected to the polymer network which make the hydrogel sticky. ${ }^{30,48}$ Some attempts have been done to achieve more uniform network structures of hydrogels. For example, a hydrogel which is formed through the self-crosslinking ability of $N, N$-dimethylacrylamide in the absence of conventional crosslinker, can imbibe up to 3000 times their weight in water and be stretched up to $1350 \%{ }^{1}$ By introducing slide-ring polyrotaxane crosslinkers into the polymer network, the resulting hydrogels are greatly stretchable and tough, and can absorb up to 620 times. $^{61}$ These reports provide us new routes to design chitosan-based superabsorbent hydrogels of high performance in the future.

Besides, the dewatering methods for the products also affect the water absorbency greatly. ${ }^{65}$ The superabsorbent material dewatered with organic agents such as methanol, ethanol and acetone, or freeze dried has much higher water uptake capacity than that of oven drying as a result of the contribution of organic agents or freeze-drying on porous structure of the product. ${ }^{66-68}$

The majority of conventional superabsorbent hydrogels are based on poly(acrylic acid) partially neutralized either before or after the polymerization step, or poly(acrylamide) then hydrolyzed to greatly enhance the water absorbency and their $\mathrm{pH}^{-}$ sensitivity swelling behavior. ${ }^{11,16,52,69,70}$ During the hydrolyzation, carboxylic acid and amide groups are converted to carboxylate salt ${ }^{16}$ shown in Fig. 4 . The $-\mathrm{COO}^{-}$groups of the partially neutralized product can convert to - $\mathrm{COOH}$ groups, and the hydrogen bonds can be formed between $-\mathrm{OH}$ and $-\mathrm{COOH}$ of the chitosan-based hydrogels in the acid solution, which is responsible for the small swelling ration when $\mathrm{pH}<5.0$. As $\mathrm{pH}$ is increased to higher than 7 , most of $-\mathrm{COOH}$ groups changes into $-\mathrm{COO}^{-}$groups and the hydrogen bonding is dissociated, and its swelling capacity is enhanced due to electrostatic repulsion from these carboxylate groups as the main driving forces. Furthermore, the cooperation of sodium carboxylate and carboxylic acid groups in a suitable ratio when acrylic acid is partially neutralized can produce higher water absorbent capability. ${ }^{71}$ In terms of the structure, they are polyanionic polymers. However, chitosan-based polyampholyte superabsorbent hydrogels show different $\mathrm{pH}$-dependent swelling behaviour compared with the conventional polyanionic polymers (Fig. 5a). ${ }^{38}$ The carboxymethyl chitosan- $g$-poly(acrylic acidco-dimethyldiallylammonium chloride) polyampholyte shows two swelling peaks not a single peak over the entire $\mathrm{pH}$ (Fig. 5b). ${ }^{52}$ Besides the $\mathrm{pH}$ sensitivity, amphoteric polyelectrolyte hydrogel also displays an electrical sensitive behaviour. ${ }^{34,72}$

Free radical polymerization is a very convenient and handy approach for preparing SHs. However, it is very difficult to control the forming of network structure and the products tend

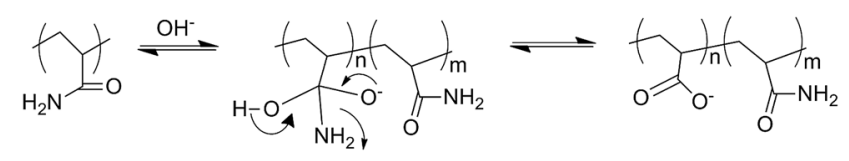

Fig. 4 Schematic representation of alkaline hydrolysis mechanism of amide sides group in polyacrylamide. Reproduced from ref. 16. Copyright (2004), with permission from Elsevier.
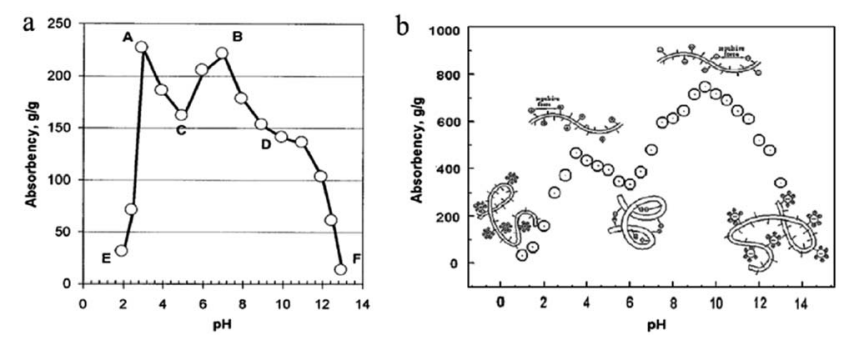

Fig. 5 Water-absorbency of superabsorbent hydrogel dependence on $\mathrm{pH}$ : (a) hydrolytic chitosan-g-polyacrylonitrile. Reproduced from ref. 38. Copyright (2003), with permission from Wiley-VCH. And (b) carboxymethyl chitosan-g-polyacrylic acid-co-dimethyldiallylammonium chloride. Reproduced from ref. 52. Copyright (2010), with permission from Elsevier. 
to have inhomogeneous networks which give rise to the decrease of swelling ability and strength. Therefore, it is necessary to develop new methods for the preparation of superabsorbent hydrogels with high performance in the future.

2.1.2 Non free radical polymerization. Apart from the free radical induced polymerization, chemical cross-linking can also be achieved through non free radical polymerization. As mentioned above, chitosan has reactive amino $\left(-\mathrm{NH}_{2}\right)$ and hydroxyl $(-\mathrm{OH})$ groups which make it possible to achieve crosslinking through the reaction between the reactive groups and carboxylic acids groups by a condensation reaction. A novel superabsorbent material is synthesized successfully through the crosslinking of chitosan with EDTA-urea adduct without free radical initiators. ${ }^{53}$ The product has a much higher water uptake (570 $\mathrm{g} \mathrm{g}^{-1}$ ) than a commercial diaper material $\left(238 \mathrm{~g} \mathrm{~g}^{-1}\right)$. Additionally, the amino group of chitosan can also react with acrylic acid by the Michael addition. ${ }^{73,74} \mathrm{H}$. Ge et al. successfully prepared $N$-carboxyethyl grafted and amide-linked chitosan-acrylic acid superabsorbent hydrogels by the thermal reaction in the absence of initiators and cross-linkers. ${ }^{55}$ It is shown in Fig. 6 that chitosan is cross-linked through the Michael addition among chitosan, monomer and the dimer of acrylic acid formed under high temperature. Furthermore, it has an equivalent water absorbency to the radical induced

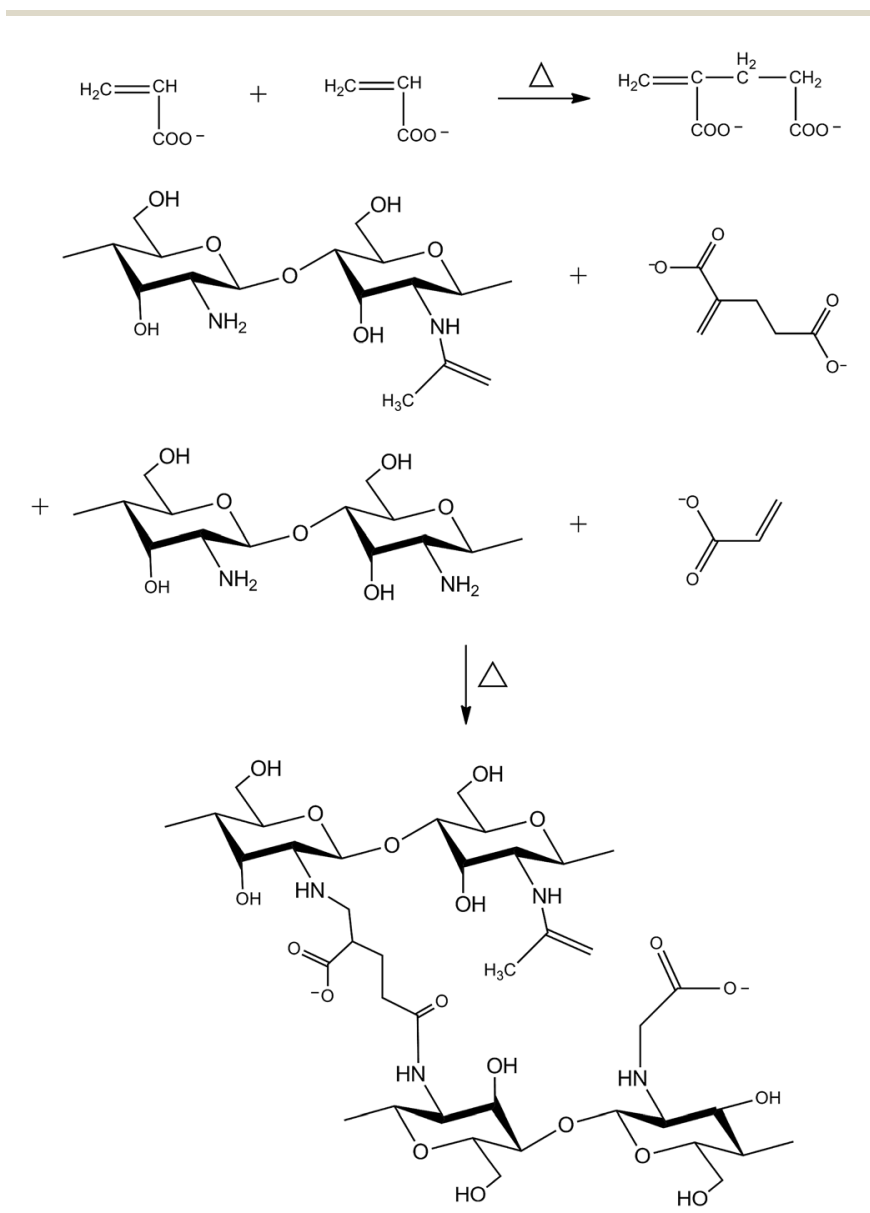

Fig. 6 Chitosan-poly(acrylic acid) superabsorbent prepared by Michael addition method through thermal reaction. Reproduced from ref. 52. Copyright (2010), with permission from Elsevier. polymerization products. It is important to note that a novel chitin-based SHs has been successfully prepared by crosslinking chitin and carboxymethylcellulose in $\mathrm{NaOH} /$ urea aqueous solution at low temperature with epichlorohydrin, ${ }^{75}$ which provides a green pathway to prepare chitosan-based SHs. Glutaraldehyde can also cross-link chitosan, carboxymethyl chitosan or starch to form a hydrogel. ${ }^{65,76,77}$

\subsection{Physical cross-linking method}

The agents used in the chemical method are often toxic and the residual cross-linkers must be removed before use in biomedical applications. Physically cross-linking such as ionic crosslinking is an efficient route to prepare three dimensional network polymers without using toxic chemical agents.

Cao et $a .^{78}$ synthesized complex gel beads with the water absorbency up to $3675 \mathrm{~g} \mathrm{~g}^{-1}$ composed of hydrolyzed polyacrylamide (HPAM) and chitosan through the electrostatic interactions among $\mathrm{Al}^{3+},-\mathrm{NH}_{3}{ }^{+}$and $-\mathrm{COO}^{-}$in a two-stage crosslinking process shown in Fig. 7. The swelling ratio of the hydrogel is much higher than that most of chitosan-based superabsorbent polymers grafted with poly(acrylic acid) ${ }^{70}$ or polyacrylamide by chemical crosslinking. This is possibly due to the porous structure on the surface of the complex. Wang et al. ${ }^{\mathbf{1 1}}$ prepared a composite hydrogel bead composed of chitosan- $g$ poly(acrylic acid), attapulgite and sodium alginate crosslinked by $\mathrm{Ca}^{2+}$ as drug delivery matrices. The composite hydrogels have good $\mathrm{pH}$ sensitivity. In addition, G. R. et al. greenly prepared a chitosan/ $\kappa$-carrageenan hydrogel through the electrostatic interactions between positively charged amino groups on chitosan and negatively charged sulfate groups on $\kappa$-carrageenan without any toxic agents (Fig. 8). ${ }^{79}$

Commonly, unmodified chitosan does not have enough water absorbency to be used as superabsorbent material. However, a pure chitosan film with high water uptake performance was fabricated without any additives such as initiators, vinyl monomers or crosslinkers by dissolving chitosan in a ternary solvent system composed of acetic acid, dioxane and DMSO, and then was freeze dried. It is demonstrated that the solvent system endowed the chitosan film micropores structure which promoted the water absorbency and swelling rate significantly. ${ }^{80}$ Due to its excellent water capability and nontoxicity, the as-chitosan film offers a very promising application in the biomedical field.

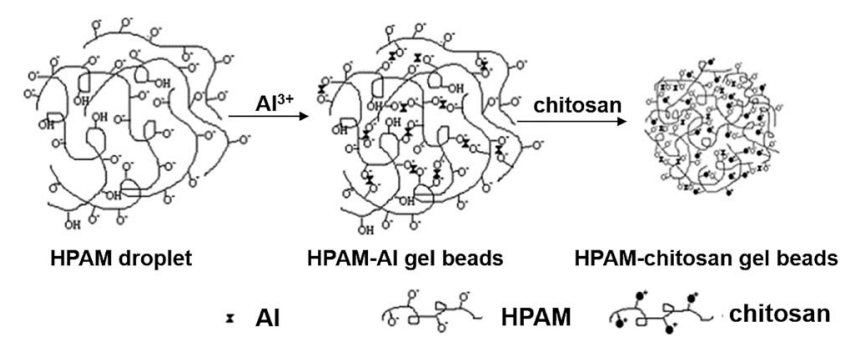

Fig. 7 Schematic representation of the formation of hydrolyzed polyacrylamide (HPAM)/chitosan gel beads. Reproduced from ref. 78 . Copyright (2010), with permission from Wiley-VCH. 

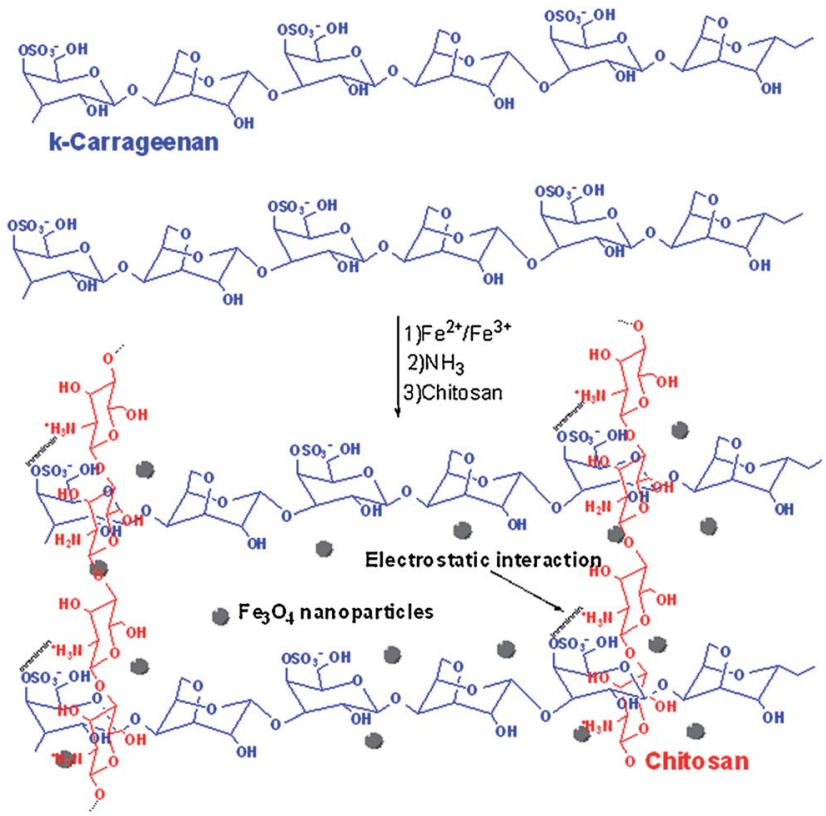

Fig. 8 Scheme for the preparation of magnetic carrageenan/chitosan complex. Reprinted from ref. 79. Copyright (2017), with permission from Elsevier.

\section{Chitosan-based superabsorbent composites}

Superabsorbent composites are hydrogels complex based on natural inorganic clay minerals, natural resources such as polysaccharides, and synthetic polymers bonding together by physical interactions. Owing to cheaper in price, and possess superior mechanical properties than non-composite counterparts. The hydrogels derived from grafting of vinyl monomers from chitosan suffer from inferior mechanical integrity. However, hydrogels with high mechanical strength are required in some applications, which can be achieved by introduced inorganic or organic compositions.

\subsection{Inorganic-chitosan composites}

Inorganic fillers such as clays, have been extensively used in the preparation of hydrogel composites due to their availability, inexpensiveness and hydrophilic nature to improve swelling properties, enhance hydrogel strength, reduce production cost and impart other excellent properties of corresponding superabsorbent materials. ${ }^{\mathbf{1}}$

In recent years, making nanocomposite is an efficient method for enhancing mechanical strength of hydrogels. Wang et $a l .{ }^{13}$ prepared chitosan- $g$-poly(acrylic acid)/montmorillonite (MMT) superabsorbent nanocomposites through in situ intercalative radical graft polymerization, and then studied the effect of one-step method and two-step method on the water absorbency and pH-responsivity (Fig. 9). They developed a convenient and time-saving approach to incorporate more montmorillonite into the composite and improve the swelling ability. Furthermore, Ferfera-Harrar et $a .^{\mathbf{8 1}}$ found the introduction of

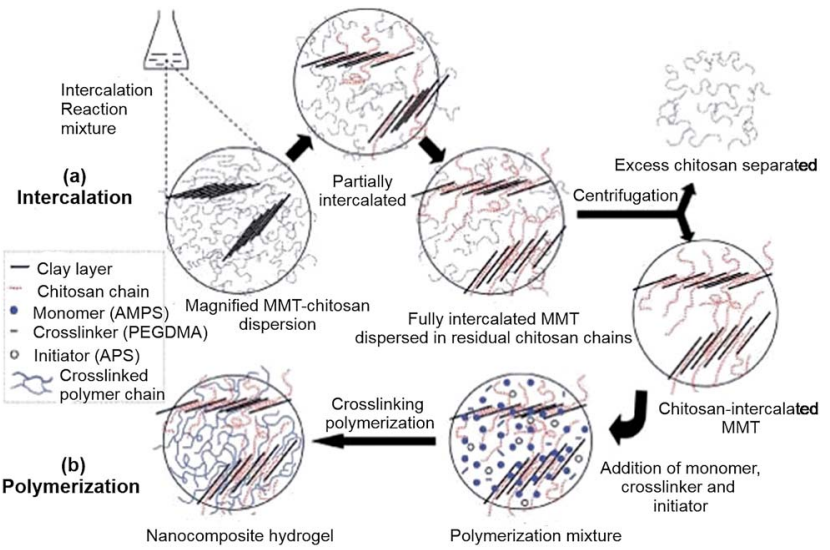

Fig. 9 Preparation of poly(AMPS)/chitosan/MMT nanocomposite hydrogels: (a) intercalation reaction, (b) crosslinking polymerization. Reproduced from ref. 83. Copyright (2009), with permission from Wiley-VCH.

montmorillonite enhanced the thermal stability and antibacterial properties of chitosan- $g$-poly(acrylamide)/ montmorillonite composites and generated a loose and more porous surface. Afterwards, K. Prasanna et al. ${ }^{82}$ studied the effect of nanoclay content on the swelling behavior of the chitosan-based composite hydrogels. It was found that the swelling capability increased with the addition of nanoclay no more than $5 \%$ because incorporation of modified nanoclay could increase the surface area and allow water to diffuse easily, and at higher contents of nanoclay beyond 5\% the ratio of hydrophilic groups reduced, therefore reducing the swelling capacity. Moreover, Kourosh et al. incorporated the chitosanintercalated montmorillonite into the polymerization of 2acrylamido-2-methylpropane-1-sulfonic acid (AMPS) in the presence of a macro-crosslinker to prepare super-swelling nanocomposite hydrogels (Fig. 9). ${ }^{83}$ Likewise, the swelling capacity, thermal stability and rubbery modulus were improved compared with those of the clay-free counterpart.

Zhang et $a l .{ }^{67}$ prepared a chitosan-g-poly(acrylic acid)/ attapulgite superabsorbent composite through the free radical graft polymerization of chitosan, acrylic acid and attapulgite in aqueous solution using APS as initiator and MBA as crosslinker. It was found that the introduction of attapulgite endowed the composite a loose and more porous structure and improved the thermal stability of the chitosan- $g$-PAA hydrogels. Furthermore, they studied the effect of the molecular weight of chitosan and dewatering solvent on water absorbency, as well as the effect of the reaction conditions, for example the amount of initiator and crosslinker, monomer concentration, reaction temperature and ration of $\mathrm{AA}$ to chitosan. Vermiculite, a layered aluminium silicate, can be modified with chitosan and acrylic acid in aqueous solution to form the chitosan- $g$-poly(acrylic acid) superabsorbent composites which presents a loose and porous structure. ${ }^{68}$ This structure contributes to the high water uptake capacity and fast swelling rate.

Krishna Rao et al. $^{\mathbf{8 4}}$ prepared polyelectrolyte complexes of hydroxyapatite and chitosan- $g$-poly(acrylamidoglycolic acid), the equilibrium swelling of hydroxyapatite polyelectrolyte 
complexes with different contents of hydroxyapatite show a general trend: when the weight percentage of hydroxyapatite increases, equilibrium swelling increases linearly for the first $200 \mathrm{~h}$ in phosphate-buffered saline. The introduction of inorganic additives can impart the composites new properties. Interestingly, rice husk ash, a rice burnt industrial waste, is mainly composed of $\mathrm{SiO}_{2}$ (94 wt\%) and abundant inorganic elements such as potassium, calcium, and phosphate contributing to plants growth. Therefore, Vaz et al. ${ }^{37}$ prepared chitosan$g$-poly(acrylic acid)/rice husk ash hydrogel composites which showed excellent adsorption capacity for methylene blue.

It can be employed in the water purification of methylene blue-contaminated waste water. Moreover, the superabsorbent composites containing rice husk ash exhibit a potential use of fertilizer. ${ }^{19}$

\subsection{Organic-chitosan composites}

Currently, the incorporation of natural polymers in the superabsorbent hydrogels formulation has been employed in order to improve applicability, biocompatibility and biodegradability. ${ }^{\mathbf{1 9}}$

Sodium humate is composed of multifunctional aliphatic components, aromatic constituents, and a great deal of functional groups, which can improve soil cluster structures, regulate plant growth, accelerate root development, and benefit the absorption of nutrient elements. ${ }^{85}$ It is reported the water absorbency of superabsorbent composite of chitosan- $g$-poly(acrylic acid)/sodium humate enhanced after the introduction of sodium humate and display slow release properties for the fertilizer. ${ }^{86}$ Starch, another abundant natural polymer, can form a semi-IPN superabsorbent hydrogel with chitosan cross-linked by glutaraldehyde shown in Fig. 10. It is found that starch increases swelling rate and ratio by increasing the hydrophilic parts and hydrogen bonds of the hydrogel with water molecule. ${ }^{76}$ Carboxymethylcellulose (CMC) is a representative watersoluble cellulose derivate with many hydrophilic groups. Ferfera-Harrar et al. elaborated superabsorbent composite-type

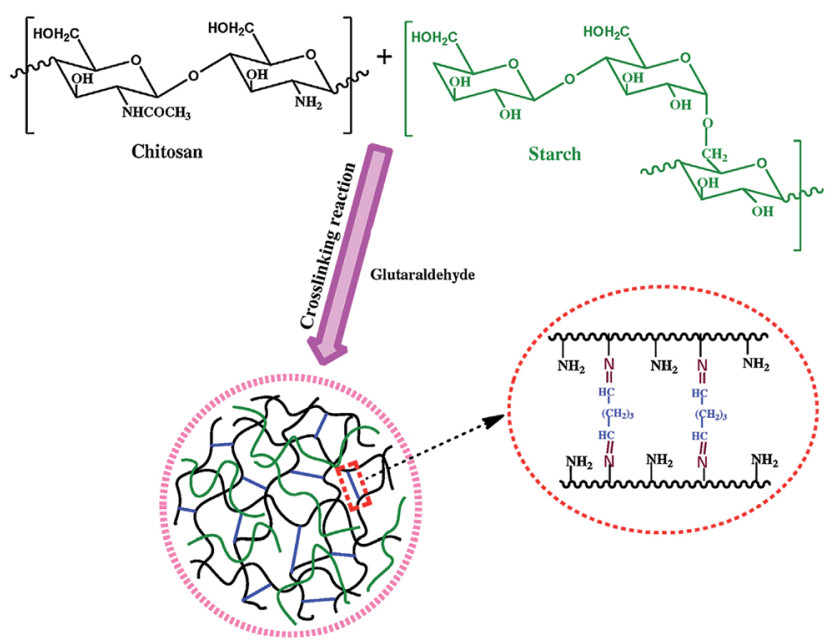

Fig. 10 Scheme of formation of chitosan/starch semi-IPN hydrogel by crosslinking reaction. Reproduced from ref. 76. Copyright (2010), with permission from Springer.
semi-IPNs composed of grafted network chitosan-graft-polyacrylamide as a matrix and carboxymethylcellulose as entrapped soluble polysaccharide. ${ }^{8}$ The presence of CMC in the composites affected the enzymatic degradation rates in both lysozyme and active slurry solutions.

It is well-known that nanofibers play a very important role in the reinforcement of hydrogel. Hence, Zhou et al. ${ }^{87}$ prepared chitosan nanofibers and then synthesized polyacrylamide/ chitosan nanofibers composite hydrogels by free radical polymerization. The products are more resilient compared with pure polyacrylamide and polyacrylamide/chitosan semi-IPN hydrogels as expected. Moreover, cellulose nanofibrils are good reinforcing fillers. The introduction of cellulose nanofibrils increases the swelling rate and capacity of the hydrogel composites based on cellulose nanofibrils, chitosan and acrylic acid via free radical polymerization using KPS as initiator and MBA as cross-linker. ${ }^{57}$ In addition, poly(vinyl alcohol) is introduced into chitosan- $g$-poly(acrylic acid) to form a semi-IPN superabsorbent hydrogels to improve the swelling rate and pH stability. ${ }^{88}$

\section{Chitosan derivatives superabsorbent hydrogels}

Although chitosan has many excellent properties, such as biodegradability, antibacterial activity, nontoxicity, the applications of chitosan are still restricted due to its poor water solubility. Therefore, a lot of chitosan derivatives such as carboxymethyl chitosan, ${ }^{\mathbf{1 2 , 4 9 , 5 4 , 8 9}}$ have been fabricated to solve this problem.

Carboxymethylchitosan is a well-known water-soluble derivative of chitosan. Chen et al. prepared a novel superabsorbent polymer from carboxymethylchitosan through free radical graft polymerization of acrylic acid onto its backbone and simultaneous cross-linking. ${ }^{49}$ Likewise, they investigated the effects of reaction conditions on the water absorbency and proposed a reasonable preparation process. Furthermore, they conducted a preliminary study on the swelling kinetics, and demonstrated that the swelling behavior of the polymers fits the process of first dynamics. Afterwards, it is reported that superabsorbent hydrogels prepared by graft copolymerization of sodium acrylate and 1-vinyl-2-pyrrolidone, a nonionic monomer onto the chain of $\mathrm{N}, \mathrm{O}$-carboxymethyl chitosan exhibit a good water uptake ability in different solutions respectively $1268 \mathrm{~g} \mathrm{~g}^{-1}$ of distilled water, $165 \mathrm{~g} \mathrm{~g}^{-1}$ of normal saline, $112 \mathrm{~g} \mathrm{~g}^{-1}$ of artificial blood and $121 \mathrm{~g} \mathrm{~g}^{-1}$ of artificial urine. In addition, a hydrogel can be obtained from cross-linked carboxymethyl chitosan by the addition of glutaraldehyde as a cross-linker. ${ }^{6,90}$ Bidgoli et $a l .{ }^{50}$ further studied the effect of three different parameters of the carboxymethylation conditions on the water absorbency of final superabsorbent product.

Quaternary ammonium chitosan, another derivative of chitosan, has good water solubility and also improves the antibacterial action. ${ }^{\mathbf{9 1 9 2}}$ The hydrogels of quaternary ammonium chitosan- $g$-poly(acrylic acid-co-acrylamide) have good antibacterial activities (Fig. 11). ${ }^{93}$ The effects of reaction factors, such as 


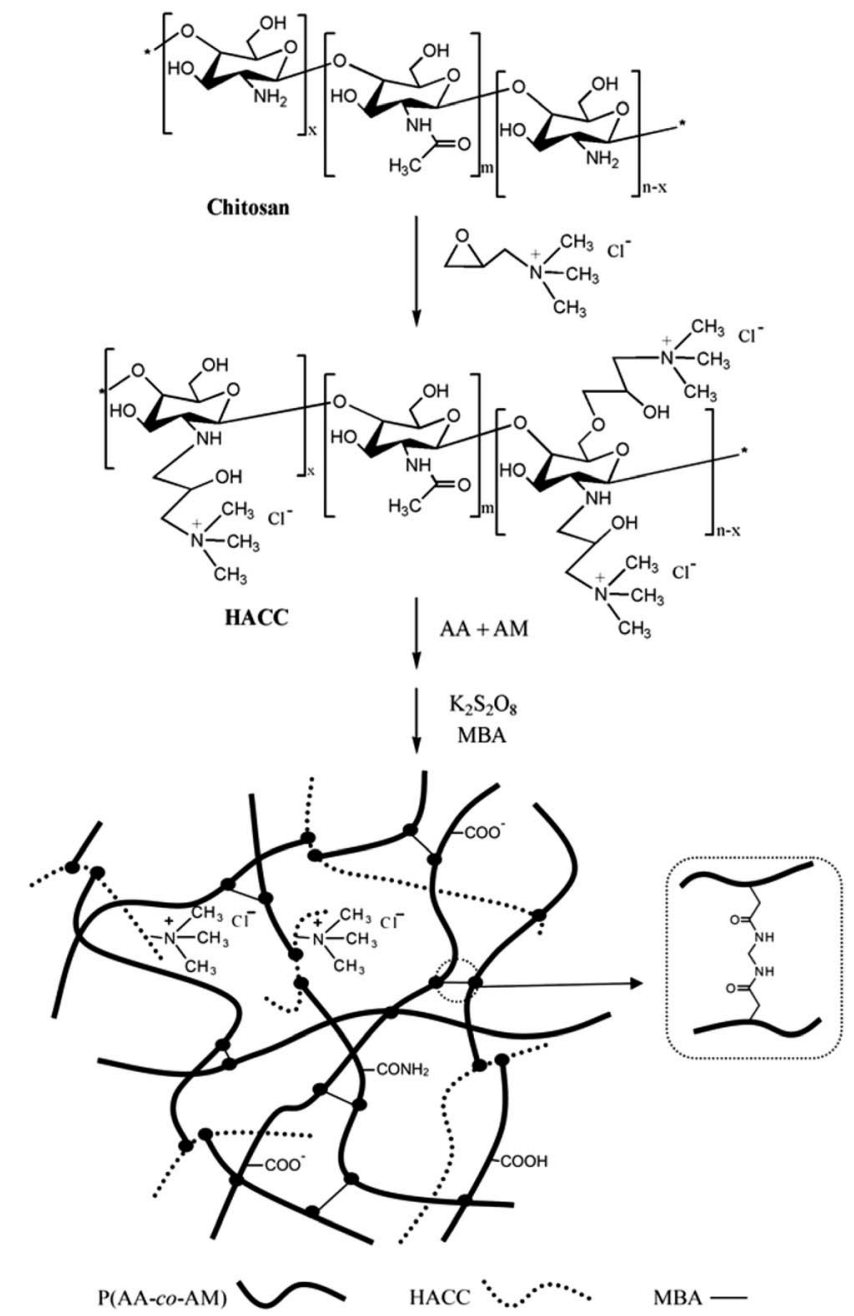

Fig. 11 Preparation of quaternary ammonium chitosan-g-poly(acrylic acid-co-acrylamide) superabsorbent hydrogels. Reprinted from ref. 93. Copyright (2017), with permission from Elsevier.

2-hydroxypropyltrimethyl ammonium chloride chitosan (HACC), initiator and cross-linker contents are investigated on the swelling behavior and antibacterial activity. And it is found that the water absorbency increased first and then decreased with the increasing of the content of reaction factor gradually. The increasing of HACC content made the antibacterial activity improve against Escherichia coli and Staphylococcus aureus but weaken with excessive HACC.

The superabsorbent hydrogels which are prepared by the chemical cross-linking of the conventional multifunctional vinyl monomers, such as MBA, are poor in degradability. So, some chitosan derivatives modified with vinyl groups can be used as macromolecular crosslinker to improve biodegradability of the superabsorbent materials. For example, $N$-maleyl chitosan as cross-linker in the preparation of poly(acrylic acidco-acrylamide) superabsorbents which has a high swelling under the optimal condition was $1812 \mathrm{~g} \mathrm{~g}^{-1}$ in distilled water. Glycidyl methacrylated chitosan, a non-toxic and biocompatible derivative is synthesized by functionalized chitosan with glycidyl methacrylate. ${ }^{94}$ Owing to non-toxicity, it is often used as cross-linker in place of glutaraldehyde in biomedical applications, ${ }^{95,96}$ which can provide us a crosslinking method to prepare chitosan based SHs.

\section{Application fields}

\subsection{Biomedical and personal hygiene}

Since their ability to absorb and retain large amounts of secreted fluids such as urine and blood, superabsorbent materials are mainly used in the fields of personal hygiene such as disposable diapers, female napkins, as well as in biomedical fields for instance, wound dressing, drug delivery and controlled release.

Diapers are sophisticated, well-engineered commercial products, and the SAP production for baby diapers accounts for about $80 \%$ of the overall superabsorbent production. ${ }^{97}$ It is important to consider the safety of the superabsorbent materials. Kosemund et al. ${ }^{3}$ provided a systematic, stepwise approach to evaluate the safety of baby diapers. It has been reported previously that sap from chitosan has antibacterial activities and could be used in infant diapers, feminine hygiene products. $^{98}$

Also, chitosan-based superabsorbent hydrogels can be used for the controlled release of drug. Mahdavinia et al. ${ }^{79}$ developed a pH-responsive and magnetic green carriers for controlled release of methotrexate anticancer drug using $\kappa$-carrageenan/ chitosan complexes. The release of the loaded methotrexate at $\mathrm{pH} 5.3$ for about $50 \%$ within $4 \mathrm{~h}$ is slower than that at $\mathrm{pH} 7.4$ for nearly $68 \%$ during 4 h. ${ }^{79}$ Shahzad et al. ${ }^{99}$ synthesized a sustained release superabsorbent particles to minimize the local irritating effect of risedronate sodium. Sohail et al. ${ }^{\mathbf{1 0 0}}$ developed chemically crosslinked chitosan-co-poly(AMPS) hydrogel based on low molecular weight chitosan for $\mathrm{pH}$-responsive and controlled drug delivery of a model drug. Samanta et al. ${ }^{101}$ prepared composite hydrogels for the release of tinidazole and theophylline. It was found that release profile of the two drugs from the hydrogels showed close fitting to Korsmeyer-Peppas model.

\subsection{Agriculture}

As is well known, water and fertilizer are essential for plant growth. However, most of water and fertilizer can not be used fully and are lost to the surroundings, which is not economical and environment friendly. Superabsorbents with slow release properties for the fertilizer have received much more attention, especially in the arid and desert environment.

Wu et al. ${ }^{102}$ developed a three-layer structure in which core is fertilizer and inner coating was chitosan and then coated with poly(acrylic acid-co-acrylamide) (P(AA-co-AM)) superabsorbent polymer to control release fertilizer and water absorbency. Furthermore, a novel multifunctional controlled-release of fertilizer with double-layer coating was prepared. ${ }^{103}$ Additionally, Noppakundilograt et al. ${ }^{\mathbf{1 0 4}}$ synthesized a tri-layer-coated NPK (nitrogen, phosphorous, potassium) fertilizer hydrogel with PVA and chitosan using the in situ inverse suspension copolymerization. Sabadini et al. ${ }^{\mathbf{1 0 5}}$ obtained a gellan gumchitosan superabsorbent. Sodium humate in the 
superabsorbent composites can enhance the water retention in soil, which may be used in desert and drought areas. ${ }^{4}$ Jamnongkan et al. prepared fertilizer controlled release hydrogel which exhibited the equilibrium swelling ratio in the range 70$300 \%$ and increased the water retention ability of the soil. ${ }^{77}$

\subsection{Water treatment}

Recently, the rapid development of industry led to more and more serious environmental problems for example water pollution. Consequently, we are facing the great challenge of the deficiency of clean water resource. So it is imperative for us to develop novel technique to treat the waste water.

A selective and high uptake adsorbent for $\mathrm{Hg}^{2+}$ made of crosslinked chitosan- $g$-poly(maleic acid) was prepared by Ge et al. ${ }^{106}$ It was found that the material exhibited a selective sorption for $\mathrm{Hg}^{2+}$ from some heavy metal ions such as $\mathrm{Cu}^{2+}$, $\mathrm{Cd}^{2+}, \mathrm{Co}^{2+}, \mathrm{Pb}^{2+}$ and $\mathrm{Hg}^{2+}$. Therefore, the chitosan- $g$-poly(maleic acid) polymers can be used to deal with the certain waste water containing $\mathrm{Hg}^{2+}$. Apart from the heavy metal ion pollution, some industrial used synthetic dyes such as methyl violet and malachite green are carcinogenic and mutagenic. Therefore, Bhattacharyya et al. ${ }^{\mathbf{1 0 7}}$ prepared a chitosan-based superabsorbent composite filled with micro- and nano-sized bentonite clay. The hydrogels present high adsorption and removal of both malachite green and methyl violet dyes from water. Chitosan-based superabsorbent material has great potential for the waste water purification. ${ }^{\mathbf{}}$

\section{Conclusions and outlook}

Chitosan-based superabsorbent hydrogels can be prepared in chemical methods including conventional free radical polymerization of AA and AAm, and non-free radical cross-linkings such as Michael addition reaction between $-\mathrm{NH}_{2}$ groups of chitosan and - $\mathrm{COOH}$ of AA, Schiff base reaction between dialdehyde and amine. The preparation mechanisms are discussed in the present review. Furthermore, incorporation of chitosan derivatives, inorganic fillers and other natural polymers, such as cellulose, starch reduces the cost, promotes the mechanical and antibacterial properties, and water absorbency. Owing to the excellent properties, chitosan-based SHs are widely used in biomedical field, agriculture and water treatment.

However, there are still great challenges to prepare superabsorbent hydrogels of excellent performance. On the one hand, hydrogels with both high strength and good water absorbency are difficult to achieve, which limits their practical use. Most of researches are focusing on the water absorbency and developing new preparation methods, few studies focus on the relationship between the network structure and properties of superabsorbent hydrogels, which can help us to design hydrogels in terms of structures. On the other hand, most of superabsorbent materials absorb much less water in salt solutions than in distilled water which exhibits poor salt resistance. In fact, in the practical application, external surrounding solutions mostly are not distilled water but contain some inorganic ionic salts such as urine. In the future, we can pay more attention to developing salt resistant superabsorbent hydrogels to extend their practical usage.

\section{Conflicts of interest}

There are no conflicts of interest to declare.

\section{Acknowledgements}

This work was financially supported by the Fundamental Research Funds for the Central Universities, and the National Natural Science Foundation of China (No. 21374099 and 51473144).

\section{Notes and references}

1 B. H. Cipriano, S. J. Banik, R. Sharma, D. Rumore, W. Hwang, R. M. Briber and S. R. Raghavan, Macromolecules, 2014, 47, 4445-4452.

2 D. J. Feng, B. Bai, C. X. Ding, H. L. Wang and Y. R. Suo, Ind. Eng. Chem. Res., 2014, 53, 12760-12769.

3 K. Kosemund, H. Schlatter, J. L. Ochsenhirt, E. L. Krause, D. S. Marsman and G. N. Erasala, Regul. Toxicol. Pharmacol., 2009, 53, 81-89.

4 C. Mo, Z. Shu-quan, L. Hua-Min, H. Zhan-bin and L. Shuqin, J. Appl. Polym. Sci., 2006, 102, 5137-5143.

5 E. Karadag, D. Saraydin, Y. Caldiran and O. Guven, Polym. Adv. Technol., 2000, 11, 59-68.

6 Application of Super Absorbent Polymers (SAP) in Concrete Construction, ed. V. Mechtcherine and H. W. Reinhardt, Springer Science \& Business Media, 2012.

7 H. Liu, Y. Bu, J. G. Sanjayan, A. Nazari and Z. Shen, Constr. Build. Mater., 2016, 104, 72-84.

8 H. Ferfera-Harrar, N. Aouaz and N. Dairi, Polym. Bull., 2015, 73, 815-840.

9 J. Zhang, X. Liang, Y. Zhang and Q. Shang, RSC Adv., 2016, 6, 52858-52867.

10 D. Feng, B. Bai, H. Wang and Y. Suo, RSC Adv., 2015, 5, 104756-104768.

11 Q. Wang, J. Zhang and A. Wang, Carbohydr. Polym., 2009, 78, 731-737.

12 Y. Chen, Y. Zhang, F. Wang, W. Meng, X. Yang, P. Li, J. Jiang, H. Tan and Y. Zheng, Mater. Sci. Eng., C, 2016, 63, 18-29.

13 J. Zhang, L. Wang and A. Wang, Ind. Eng. Chem. Res., 2007, 46, 2497-2502.

14 J. Wu, Y. Wei, J. Lin and S. Lin, Polymer, 2003, 44, 65136520.

15 Y. Bao, J. Ma and N. Li, Carbohydr. Polym., 2011, 84, 76-82. 16 G. R. Mahdavinia, A. Pourjavadi, H. Hosseinzadeh and M. J. Zohuriaan, Eur. Polym. J., 2004, 40, 1399-1407.

17 M. R. Guilherme, A. V. Reis, S. H. Takahashi, A. F. Rubira, J. P. A. Feitosa and E. C. Muniz, Carbohydr. Polym., 2005, 61, 464-471.

18 J. Wu, X. Deng and X. Lin, Radiat. Phys. Chem., 2013, 83, 9097. 
19 F. H. A. Rodrigues, A. R. Fajardo, A. G. B. Pereira, N. M. P. S. Ricardo, J. P. A. Feitosa and E. C. Muniz, J. Polym. Res., 2012, 19, 2351-2357.

20 J. Gao, Q. Yang, F. Ran, G. Ma and Z. Lei, Appl. Clay Sci., 2016, 132-133, 739-747.

21 M. Zhang, Z. Cheng, T. Zhao, M. Liu, M. Hu and J. Li, J. Agric. Food Chem., 2014, 62, 8867-8874.

22 J. F. Mukerabigwi, S. J. Lei, H. L. Wang, S. Y. Luo, X. Y. Ma, J. Qin, X. Y. Huang and Y. Cao, RSC Adv., 2015, 5, 8373283742.

23 J. Kollár, M. Mrlík, D. Moravčíková, Z. Kroneková, T. Liptaj, I. Lacík and J. Mosnáček, Macromolecules, 2016, 49, 40474056.

24 H. Yi, L.-Q. Wu, W. E. Bentley, R. Ghodssi, G. W. Rubloff, J. N. Culver and G. F. Payne, Biomacromolecules, 2005, 6, 2881-2894.

25 J. Duan, X. Liang, Y. Cao, S. Wang and L. Zhang, Macromolecules, 2015, 48, 2706-2714.

26 J. Nie, Z. Wang, J. Zhang, L. Yang, Y. Pang and Q. Hu, RSC Adv., 2015, 5, 68243-68250.

27 A. Anitha, S. Sowmya, P. T. S. Kumar, S. Deepthi, K. P. Chennazhi, H. Ehrlich, M. Tsurkan and R. Jayakumar, Prog. Polym. Sci., 2014, 39, 1644-1667.

28 T. T. Nge, N. Hori, A. Takemura and H. Ono, J. Appl. Polym. Sci., 2004, 92, 2930-2940.

29 S. Elkholy, K. D. Khalil, M. Z. Elsabee and M. Eweis, J. Appl. Polym. Sci., 2007, 103, 1651-1663.

30 F. Engelhardt, G. Ebert and R. Funk, Adv. Mater., 1992, 4, 227-230.

31 M. P. Raju and K. M. Raju, J. Appl. Polym. Sci., 2001, 80, 2635-2639.

32 J. Ma, X. Li and Y. Bao, RSC Adv., 2015, 5, 59745-59757.

33 G. A. Mun, Z. S. Nurkeeva, S. A. Dergunov, I. K. Nam, T. P. Maimakov, E. M. Shaikhutdinov, S. C. Lee and K. Park, React. Funct. Polym., 2008, 68, 389-395.

34 J. Chen, L.-x. Gao, X. Han, T. Chen, J. Luo, K. Liu, Z. Gao and W. Zhang, Mater. Chem. Phys., 2016, 169, 105-112.

35 K. Kabiri, H. Omidian, S. A. Hashemi and M. J. ZohuriaanMehr, Eur. Polym. J., 2003, 39, 1341-1348.

36 L. Yin, L. Fei, F. Cui, C. Tang and C. Yin, Biomaterials, 2007, 28, 1258-1266.

37 M. G. Vaz, A. G. B. Pereira, A. R. Fajardo, A. C. N. Azevedo and F. H. A. Rodrigues, Water, Air, Soil Pollut., 2016, 228.

38 A. Pourjavadi, G. R. Mahdavinia and M. J. Zohuriaan-Mehr, J. Appl. Polym. Sci., 2003, 90, 3115-3121.

39 S. A. Dergunov, I. K. Nam, T. P. Maimakov, Z. S. Nurkeeva, E. M. Shaikhutdinov and G. A. Mun, J. Appl. Polym. Sci., 2008, 110, 558-563.

40 S. Ismail, E.-S. Hegazy, N. Shaker, E. Badr and N. Deghiedy, J. Macromol. Sci., Part A: Pure Appl.Chem., 2009, 46, 967-974.

41 D. K. Singh and A. R. Ray, J. Appl. Polym. Sci., 1997, 66, 869877.

42 M. F. A. Taleb, Polym. Bull., 2008, 61, 341-351.

43 L. Zhao, H. Mitomo, N. Nagasawa, F. Yoshii and T. Kume, Carbohydr. Polym., 2003, 51, 169-175.

44 M. H. Casimiro, M. L. Botelho, J. P. Leal and M. H. Gil, Radiat. Phys. Chem., 2005, 72, 731-735.
45 S. Saber-Samandari, M. Gazi and E. Yilmaz, Polym. Bull,, 2012, 68, 1623-1639.

46 T. Liu, L. Qian, B. Li, J. Li, K. Zhu, H. Deng, X. Yang and X. Wang, Carbohydr. Polym., 2013, 94, 261-271.

47 H. Omidian, S. A. Hashemi, P. G. Sammes and I. G. Meldrum, Polymer, 1998, 39, 3459-3466.

48 Preparation methods of superabsorbent polyacrylates, ed. F. L. Buchholz and N. A. Peppas, ACS Symposium Series, 1994, vol. 573, pp. 27-38.

49 Y. Chen and H. M. Tan, Carbohydr. Res., 2006, 341, 887-896.

50 H. Bidgoli, A. Zamani and M. J. Taherzadeh, Carbohydr. Res., 2010, 345, 2683-2689.

51 S. Chatterjee, T. Chatterjee and S. H. Woo, Bioresour. Technol., 2010, 101, 3853-3858.

52 C. Yu, L. Yun-fei, T. Huan-lin and T. Hui-min, Carbohydr. Polym., 2010, 81, 365-371.

53 A. Narayanan and R. Dhamodharan, Carbohydr. Polym., 2015, 134, 337-343.

54 Y. Chen, Y.-F. Liu, H.-M. Tan and J.-x. Jiang, Carbohydr. Polym., 2009, 75, 287-292.

55 H. Ge and S. Wang, Carbohydr. Polym., 2014, 113, 296-303.

56 F. H. A. Rodrigues, A. G. B. Pereira, A. R. Fajardo and E. C. Muniz, J. Appl. Polym. Sci., 2013, 128, 3480-3489.

57 C. Spagnol, F. H. A. Rodrigues, A. G. B. Pereira, A. R. Fajardo, A. F. Rubira and E. C. Muniz, Carbohydr. Polym., 2012, 87, 2038-2045.

58 A. Pourjavadi, A. M. Harzandi and H. Hosseinzadeh, Eur. Polym. J., 2004, 40, 1363-1370.

59 S. C. Hsu, T. M. Don and W. Y. Chiu, Polym. Degrad. Stab., 2002, 75, 73-83.

60 V. Singh, D. N. Tripathi, A. Tiwari and R. Sanghi, J. Appl. Polym. Sci., 2005, 95, 820-825.

61 A. Bin Imran, K. Esaki, H. Gotoh, T. Seki, K. Ito, Y. Sakai and Y. Takeoka, Nat. Commun., 2014, 5, 5124.

62 S. Zhang, Z. Shi, H. Xu, X. Ma, J. Yin and M. Tian, Soft Matter, 2016, 12, 2575-2582.

63 J. Zhang, M. W. Sun, L. Zhang and X. M. Xie, J. Appl. Polym. Sci., 2003, 90, 1851-1856.

64 D. J. Arriola, S. S. Cutié, D. E. Henton, C. Powell and P. B. Smith, J. Appl. Polym. Sci., 1997, 63, 439-451.

65 A. Zamani and M. J. Taherzadeh, Ind. Eng. Chem. Res., 2010, 49, 8094-8099.

66 K. Kabiri and M. J. Zohuriaan-Mehr, Macromol. Mater. Eng., 2004, 289, 653-661.

67 J. Zhang, Q. Wang and A. Wang, Carbohydr. Polym., 2007, 68, 367-374.

68 Y. Xie and A. Wang, J. Polym. Res., 2009, 16, 143-150.

69 J. Liu, Y. Zheng, W. Wang and A. Wang, J. Appl. Polym. Sci., 2009, 114, 643-652.

70 H. Ge, W. Pang and D. Luo, Carbohydr. Polym., 2006, 66, 372-378.

71 J. H. Wu, J. M. Lin, G. Q. Li and C. R. Wei, Polym. Int., 2001, 50, 1050-1053.

72 J. Shang, Z. Shao and X. Chen, Polymer, 2008, 49, 5520-5525.

73 H. Sashiwa, N. Yamamori, Y. Ichinose, J. Sunamoto and S.-I. Aiba, Macromol. Biosci., 2003, 3, 231-233. 
74 H. Sashiwa, N. Yamamori, Y. Ichinose, J. Sunamoto and S.-I. Aiba, Biomacromolecules, 2003, 4, 1250-1254.

75 H. Tang, H. Chen, B. Duan, A. Lu and L. Zhang, J. Mater. Sci., 2013, 49, 2235-2242.

76 F. A. Ngwabebhoh, M. Gazi and A. A. Oladipo, Chem. Eng. Res. Des., 2016, 112, 274-288.

77 T. Jamnongkan and S. Kaewpirom, J. Polym. Environ., 2010, 18, 413-421.

78 J. Cao, Y. Tan, Y. Che and Q. Ma, J. Appl. Polym. Sci., 2010, 116, 3338-3345.

79 G. R. Mahdavinia, A. Mosallanezhad, M. Soleymani and M. Sabzi, Int. J. Biol. Macromol., 2017, 97, 209-217.

80 X. Wang, T. Lou, W. Zhao and G. Song, Carbohydr. Polym., 2016, 153, 253-257.

81 H. Ferfera-Harrar, N. Aiouaz, N. Dairi and A. S. HadjHamou, J. Appl. Polym. Sci., 2014, 131, 39747-39761.

82 K. Prasanna, M. V. Deepthi, A. Ashamol and R. R. N. Sailaja, Polym.-Plast. Technol. Eng., 2013, 52, 352-357.

83 K. Kabiri, H. Mirzadeh, M. J. Zohuriaan-Mehr and M. Daliri, Polym. Int., 2009, 58, 1252-1259.

84 K. S. V. Krishna Rao, I. Chung and C.-S. Ha, React. Funct. Polym., 2008, 68, 943-953.

85 J. P. Zhang, A. Li and A. Q. Wang, Polym. Adv. Technol., 2005, 16, 813-820.

86 J. Liu, Q. Wang and A. Wang, Carbohydr. Polym., 2007, 70, 166-173.

87 C. Zhou and Q. Wu, Colloids Surf., B, 2011, 84, 155-162.

$88 \mathrm{~J}$. Liu, W. Wang and A. Wang, Polym. Adv. Technol., 2011, 22, 627-634.

89 T. Sun, P. Xu, Q. Liu, J. Xue and W. Xie, Eur. Polym. J., 2003, 39, 189-192.

90 A. Zamani, D. Henriksson and M. J. Taherzadeh, Carbohydr. Polym., 2010, 80, 1091-1101.
91 Z. Jia, D. shen and W. Xu, Carbohydr. Res., 2001, 333, 1-6. 92 C. H. Kim, J. W. Choi, H. J. Chun and K. S. Choi, Polym. Bull., 1997, 38, 387-393.

93 G. He, W. Ke, X. Chen, Y. Kong, H. Zheng, Y. Yin and W. Cai, React. Funct. Polym., 2017, 111, 14-21.

94 N. Flores-Ramírez, E. A. Elizalde-Peña, S. R. Vásquez-García, J. González-Hernández, A. Martinez-Ruvalcaba, I. C. Sanchez, G. Luna-Bárcenas and R. B. Gupta, J. Biomater. Sci., Polym. Ed., 2005, 16, 473-488.

95 B. Choi, S. Kim, B. Lin, B. M. Wu and M. Lee, ACS Appl. Mater. Interfaces, 2014, 6, 20110-20121.

96 Z. Cao, Q. Yang, C. Fan, L. Liu and L. Liao, J. Appl. Polym. Sci., 2015, 132, 42459-42466.

97 M. J. Zohuriaan-Mehr, H. Omidian, S. Doroudiani and K. Kabiri, J. Mater. Sci., 2010, 45, 5711-5735.

98 H. K. No, N. Y. Park, S. H. Lee, H. J. Hwang and S. P. Meyers, J. Food Sci., 2002, 67, 1511-1514.

99 M. K. Shahzad, N. I. Bukhari, G. Murtaza and S. Karim, Curr. Pharm. Anal., 2016, 12, 114-120.

100 M. Sohail, M. Ahmad, M. U. Minhas, L. Ali, I. Khalid and H. Rashid, Int. J. Pharm., 2015, 487, 110-119.

101 H. S. Samanta and S. K. Ray, Carbohydr. Polym., 2014, 106, 109-120.

102 L. Wu and M. Liu, Carbohydr. Polym., 2008, 72, 240-247.

103 X. Wang, S. Lu, C. Gao, X. Xu, Y. Wei, X. Bai, C. Feng, N. Gao, M. Liu and L. Wu, RSC Adv., 2014, 4, 18382-18390.

104 S. Noppakundilograt, N. Pheatcharat and S. Kiatkamjornwong, J. Appl. Polym. Sci., 2015, 132, 41249-41260.

105 R. C. Sabadini, V. C. A. Martins and A. Pawlicka, Cellulose, 2015, 22, 2045-2054.

106 H. Ge and T. Hua, Carbohydr. Polym., 2016, 153, 246-252.

107 R. Bhattacharyya and S. K. Ray, Appl. Clay Sci., 2014, 101, 510-520. 